\title{
Laparoscopic fundoplication improves oesophageal motility - a prospective study
}

\author{
Wiesław Tarnowski, Adam Kiciak, Katarzyna Borycka-Kiciak, Adam Ciesielski, Artur Binda, Naser Dib \\ General and Gastrointestinal Surgery Department CMKP, Warsaw, Poland
}

Videosurgery and other miniinvasive techniques 2011; 6 (2): 73-83

DOI: 10.5114/wiitm.2011.23213

\begin{abstract}
Introduction: In the presented series of a hundred consecutive cases the authors tried to assess objectively the efficacy of surgical treatment for gastroesophageal reflux disease.

Aim: To assess the influence of the procedure on oesophageal motility and the lower oesophagus sphincter.

Material and methods: Thirty-seven female and 63 male patients were qualified to participate in the study. Based on the preoperative manometry results patients were qualified for laparoscopic complete fundoplication (Nissen procedure) or incomplete fundoplication (Toupet's procedure). The control examination was performed one year after surgical treatment.

Results: Taking into account the preoperative oesophageal manometry results, 67 Nissen fundoplications and 33 Toupet's fundoplications were performed. The mean age was 51.54 years. Postoperative mortality was $0 \%$. Assessing the oesophageal motility it was concluded that the values of particular parameters of the lower oesophageal sphincter (LES) - total length, length of the abdominal portion - increased significantly $(p<0.001)$ and the mean resting pressure in the LES increased statistically significantly independently of the operative method. A significant influence of the procedure on the peristaltic contraction amplitude, its duration, percentage of non-peristaltic contractions and the percentage of low-amplitude contractions was observed. The greatest changes of the clinically significant parameters - the percentage of low-amplitude contractions and the number of non-peristaltic contractions - were observed in the group of patients with impaired oesophageal motility. During the postoperative period a decrease of the percentage of low-amplitude contractions and an increase of peristaltic contractions were observed. Both parameters were statistically significant.

Conclusions: Antireflux procedures regardless of the technique used cause normalization of lower oesophageal sphincter function. All anatomical parameters of the lower oesophageal sphincter return to normal values. Following the antireflux procedures the oesophageal motility significantly improves clinically, especially in the group of patients with impaired oesophageal motility.
\end{abstract}

Key words: laparoscopic surgery, gastroesophageal reflux, oesophageal motility.

\section{Introduction}

Receding of the gastric contents to the oesophagus is called gastroesophageal reflux and can lead to inflammatory changes in the oesophagus and oesophageal mucosa damage.
Frequent recurrences of the disease, laceration and ulceration formation and healing of these changes in the oesophageal mucosa can lead to the stricture or to the replacement of the stratified squamous epithelium by the cylindrical epithelium with intestinal metaplasia with varying degrees of dyspla- 
sia, thus leading to the development of Barrett's oesophagus. Evolution of the changes characteristic for Barrett's oesophagus can consequently lead to the development of adenocarcinoma of the lower part of the oesophagus. The frequency of gastroesophageal reflux significantly exceeds the frequency of other oesophageal diseases and one can say that it is a condition of social importance.

The body of the oesophagus is responsible for moving the portion of the ingested food towards the stomach. For this advancement to be effective, the peristaltic wave created in the upper oesophageal sphincter should have correct speed and amplitude of contraction. For the peristaltic wave to be effective it should have the contraction amplitude in the range of $30-150 \mathrm{mmHg}$, the contraction should last about $2 \mathrm{~s}$ and advance with the speed of $2-4 \mathrm{~cm} / \mathrm{s}$. Kahrilas demonstrated that a peristaltic wave of an amplitude lower than $30 \mathrm{mmHg}$ does not advance the food bolus effectively [1, 2]. Progress of the peristaltic wave from the top towards the cardia depends on the electric impulse generation in the swallowing centre. That impulse, by the efferent fibres of the vagus nerve, stimulates subsequent sections of the oesophagus to contract. This kind of peristaltic wave arising as a result of swallowing is called the primary peristaltic wave as distinct from the secondary peristaltic wave initiated as a result of e.g. the oesophageal wall stretching. The secondary peristaltic wave can form as a reflex activity being a response to the stimulus that starts in the lower part of the oesophagus and is not connected with the pharyngeal movement. Physiologically, the oesophageal pressure has a negative value $(-6 \mathrm{mmHg})$ and fluctuates along with the respiratory movements of the thorax.

From the bottom the oesophagus is confined by the lower oesophageal sphincter (LES). The evaluation of the LES competence takes into account its three parameters: total length, length of the abdominal portion and the resting pressure. Total length of the sphincter is about $4 \mathrm{~cm}$; of this the abdominal portion is $2 \mathrm{~cm}$. The resting pressure in the LES should exceed $10 \mathrm{mmHg}$. It is encircled by the right diaphragmatic crus. Considering the value of the lower oesophageal sphincter as an antireflux barrier one should not treat it as an individual structure but one should rather talk about the anatomy of the gastroesophageal junction, which consists of a few components, and only in total do they constitute the virtual antireflux barrier.
Commonly accepted investigations essential for the proper diagnosis of the disease, its causes and classification for the correct treatment are:

- radiological examination,

- endoscopy,

- 24-hour impedance study/oesophageal pH-metry, - oesophageal manometry.

The main diagnostic tool for the assessment of the oesophageal motility and the parameters of the upper and lower oesophageal sphincter is oesophageal manometry. It allows the diagnosis of the primary motility disorders such as achalasia, diffuse oesophageal spasm, 'nutcracker oesophagus', hypertensive LES, non-specific oesophageal motility disturbances or disorders secondary to other current diseases such as scleroderma, dermatomyositis, diabetes mellitus or neuropathies of various origin [3-8].

Manometric measurements can be performed with portable recorders (ambulatory manometry) or stationary recorders. Ambulatory manometry was introduced to the investigations of oesophageal motility in non-cardiac chest pain in the mid-eighties. Later, its use was extended to reflux disease and other motility disorders.

The value of oesophageal manometry in reflux disease diagnostics is not fully accepted. It is known that on the basis of manometry one cannot make a diagnosis but without it one cannot diagnose the causes of GERD in full. This refers in particular to LES competence as one of the basic components of the antireflux barrier. Its incompetence is associated with severe, complicated forms of GERD. Multiple studies have concluded that together with the development of reflux disease motility of the oesophagus becomes impaired [9-18]. Inefficient oesophageal motility means the presence of $30 \%$ or more of contractions of amplitude lower than $30 \mathrm{mmHg}$ in the distal part of the oesophagus [3, 19]. This statement continues to have an influence on the choice of operative technique by many surgeons. At present, there is no other examination that would deliver so much information on the activity of the oesophagus as manometry.

\section{Aim}

The aim of this study was to evaluate the influence of antireflux surgery on oesophageal motility and the lower oesophagus sphincter. The obtained results 
were critically assessed and they had a direct influence on modification of the surgical technique during the trial period. The study had a prospective character.

\section{Material and methods}

The material consists of a hundred consecutive patients treated surgically for gastrointestinal reflux disease, who gave informed consent to participate in the study. The study group consisted of 37 female and 63 male patients. In all patients uniform prospective preoperative and postoperative assessment was conducted. Main clinical symptoms assessed were: heartburn, retrosternal pain and pain in the upper part of the epigastrium, excessive belching, nausea, regurgitation, and dysphagia.

During the preoperative period all patients had the following examinations performed:

- upper gastrointestinal tract endoscopy,

- contrast radiological examination of the upper gastrointestinal tract,

- oesophageal manometry,

- 24-hour pH-metry.

One year after the procedure in all patients ( $n=100)$ oesophageal motility was assessed again by manometry examination. Oesophageal manometry was performed using a hydraulic pump with eightchannel catheters with concentric lateral openings and a water flow speed of $5 \mathrm{ml} / \mathrm{min}$ (Synectics Medical, Sweden).

During the examination the following parameters were assessed:

- total length of LES (N: $3.7 \mathrm{~cm}$ [2.6-5.4]),

- length of abdominal portion of LES (N: $2.2 \mathrm{~cm}$ [1.13.4]),

- mean resting pressure in LES ( $\mathrm{N}: 13.8 \mathrm{mmHg}$ [8.026.5]).

Mean values (acknowledged standard) are presented in parentheses, and the range of the $5^{\text {th }}$ to the $95^{\text {th }}$ percentile in square brackets.

Oesophageal motility was examined using three sensors spaced every $5 \mathrm{~cm}$, with the lowest sensor placed $3 \mathrm{~cm}$ above the upper edge of the lower oesophageal sphincter, the next one $8 \mathrm{~cm}$ above the LES and the last one $13 \mathrm{~cm}$ above the LES, by giving the patient to swallow 10 times $5 \mathrm{ml}$ of room temperature water. In the manometry examination of the oesophageal corpus the following parameters were evaluated:
- mean amplitude value (MAV):

Normal values for particular levels above the LES:

$-3 \mathrm{~cm}-93 \mathrm{mmHg}$ (36-190),

$-8 \mathrm{~cm}-93 \mathrm{mmHg}(38-180)$,

$-13 \mathrm{~cm}-76 \mathrm{mmHg}(30-164)$;

- mean duration of peristaltic contraction (MD):

$-3 \mathrm{~cm}-3.7 \mathrm{~s}(2.4-7.0)$,

$-8 \mathrm{~cm}-3.6 \mathrm{~s}(2.6-5.7)$,

$-13 \mathrm{~cm}-3.3 \mathrm{~s}(2.4-5.2)$

Values for the $5^{\text {th }}$ and $95^{\text {th }}$ percentile respectively are given in parentheses:

- number of non-peristaltic contractions expressed as a percentage,

- number of peristaltic contractions,

- number of simultaneous contractions,

- number of low-amplitude contractions.

The proportion of non-peristaltic contractions was calculated on the basis of the number of contractions of the amplitude lower than $30 \mathrm{mmHg}$ in the lower part of the oesophagus that is $3 \mathrm{~cm}$ above the LES.

Simultaneous contractions are contractions in which the rate of the peristaltic wave's propagation is higher than $20 \mathrm{~cm} / \mathrm{s}$, which means that the oesophageal contraction takes place practically at all three levels. Low-amplitude contractions are contractions of amplitude lower than $30 \mathrm{mmHg}$. Oesophageal motility was assessed as impaired if at least $30 \%$ of contractions were non-peristaltic [34].

The results obtained by Constantini et al. were accepted as the normal values [3].

\section{Statistical analysis}

Statistical analysis was performed using CSS/Statistica software, 5.1 Pl version.

\section{Results}

Hundred patients, 37 female and 63 male, operated on because of gastroesophageal reflux disease, who gave informed consent to participate in the study, were qualified for prospective evaluation. The mean age was 51.54 years. The mean duration of symptoms was 6.7 years. The majority of patients were between 45 and 65 years of age. Mean age was 49.4 years in the group of patients who had the Nissen procedure and was lower than in the Toupet procedure group -55.8 years of age.

Taking into account the preoperative oesophageal manometry results, 67 patients were qualified for Nissen fundoplication - the group with the correct 
oesophageal motility (group N); and 33 patients for Toupet fundoplication - the group with primarily impaired oesophageal motility (group T). Postoperative mortality was $0 \%$ for the whole study group.

Oesophageal motility assessment was conducted by comparison of the data obtained from the manometry examinations performed before and a year after the procedure. Direct comparison of the data allowed evaluation of the virtual impact of the procedure on the motility of the oesophageal corpus and the lower oesophageal sphincter.

\section{Assessment of the oesophageal corpus motility}

Evaluating the oesophageal corpus motility, without the subdivision based on the type of the performed procedure, it was noted that the maximal changes regarded the inferior, supracardial part of the oesophagus. The mean amplitude value (MAV) of the peristaltic contraction $3 \mathrm{~cm}$ above the LES (MAV3A) was $69.32 \mathrm{mmHg}$ before the procedure, and following the procedure (MAV3B) was $90.3 \mathrm{mmHg}$, reaching statistical significance $(p<0.003)$. Improve- ment of the mean amplitude values at the level of $8 \mathrm{~cm}$ above the LES was also statistically significant, although not as pronounced; the values are 58.90 $\mathrm{mmHg}$ (MAV8A) and $67.96 \mathrm{mmHg}$ (MAV8B) respectively $(p<0.001)$. They do not reach statistically significant values at $13 \mathrm{~cm}$ above the LES $-41.29 \mathrm{mmHg}$ vs. $42.56 \mathrm{mmHg}(p<0.34)$ (Figure 1).

It is noticeable that the improvement of the mean amplitude values of the peristaltic contraction, the parameter with probably the greatest influence on the food bolus advancement, refers mainly to the inferior part of the oesophagus. Evaluating this parameter before and after the Nissen procedure, a significant difference is seen only at the level of $3 \mathrm{~cm}$ above the LES - (MAV3A) 82.90 mmHg vs. (MAV3B) $98.53 \mathrm{mmHg}$ $(p<0.009)$. At the remaining levels, that is $8 \mathrm{~cm}$ and $13 \mathrm{~cm}$ above the LES, the differences are small and practically with no importance, though there is a trend towards an increase of the mean amplitude value. The greatest changes are observed after the Toupet procedure, and thus in the group with impaired oesophageal motility. Improvement of the mean amplitude value of the peristaltic contraction is greatest $3 \mathrm{~cm}$ above the cardia, similarly as in the previous
A

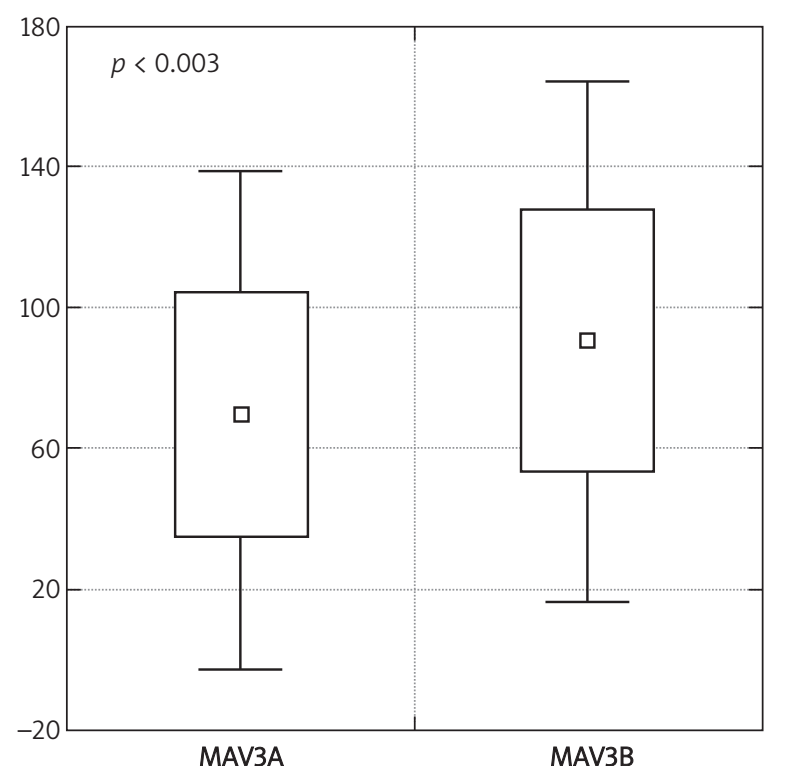

B

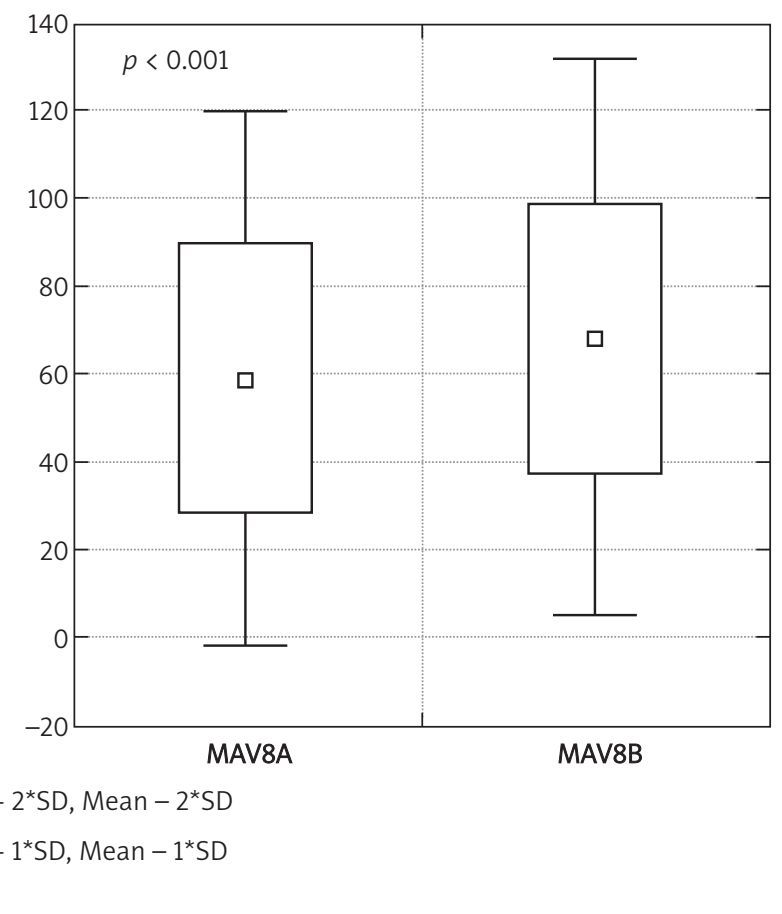

Figure 1. Mean amplitude value changes before and after the procedure at the level of 3 and $8 \mathrm{~cm}$ above the LES in the whole study group 
groups, and is (MAV3A) $41.77 \mathrm{mmHg}$ vs. (MAV3B) $73.59 \mathrm{mmHg}$ respectively $(p<0.006)$. The higher above the cardia, the smaller the changes in the mean amplitude value of the contraction.

Analysing the mean duration of the peristaltic contraction (MD) it is noticeable that on all observation levels there was a change towards prolongation of the duration. In the whole study group, and thus without the subdivision into procedure types, the following results were obtained: $3 \mathrm{~cm}$ above the LES (MD3A) $3.6 \mathrm{~s}$ vs. (MD3B) $4.19 \mathrm{~s}(p<0.006) ; 8 \mathrm{~cm}$ above the LES (MD8A) $3.29 \mathrm{~s}$ vs. (MD8B) $3.81 \mathrm{~s}$ $(p<0.009) ; 13 \mathrm{~cm}$ above the LES (MD13A) $2.71 \mathrm{~s}$ vs. (MD13B) $3.25 \mathrm{~s}(p<0.003)$ (Figure 2).

The greatest changes in the extent of the motility of the oesophagus corpus parameters were observed when the proportion of the non-peristaltic, simultaneous and peristaltic contractions was assessed. Comparing the proportion of the non-peristaltic contractions (PRC_SKN) in the whole study population, after both Nissen and Toupet procedures, its greatest decrease was observed following Toupet fundoplication from $64.2 \%$ before the procedure (PRC SKN1) to $21.5 \%$ after the procedure (PRC SKN2) $(p<0.004)$. In the remaining groups it was noted that their number decreased, although not as clearly. Consequently, in the whole study group their number decreased from $26.86 \%$ to $12.2 \%(p<0.001)$. In the group of patients after the Nissen procedure the observed changes are not as significant, since the proportion of non-peristaltic contractions is minimal (8.18\%). Therefore, following the Toupet procedure, that is in the group with impaired oesophageal motility, the improvement of this parameter is most crucial (Figure 3).

Similarly, the greatest improvement following the Toupet procedure is expressed in the number of lowamplitude contractions (IL_SKA). During the preoperative period the number of low-amplitude contractions (IL_SKA1) (that is below $30 \mathrm{mmHg}$ ) was in this group 4.42 and 1.75 after the procedure (IL_SKA2) $(p<0.008)$ (Figure 4).

In none of the remaining groups were the changes so significant. Thereby in the preoperative period the absolute number of low-amplitude contractions was substantially lower. In the whole study population it was 2.51 and in the group following the Nissen procedure 1.56. In both groups its decrease was noted but from the point of view of
A

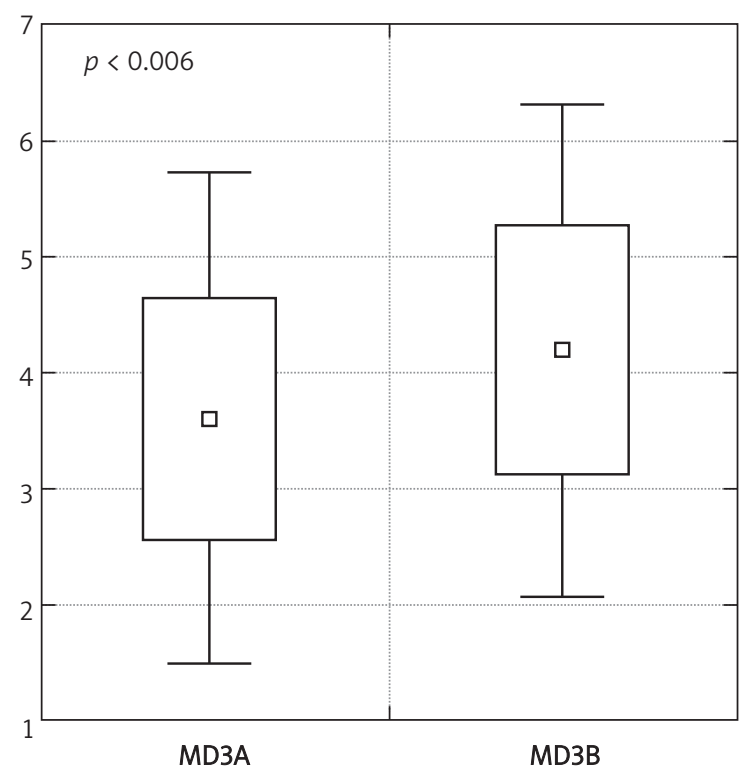

B

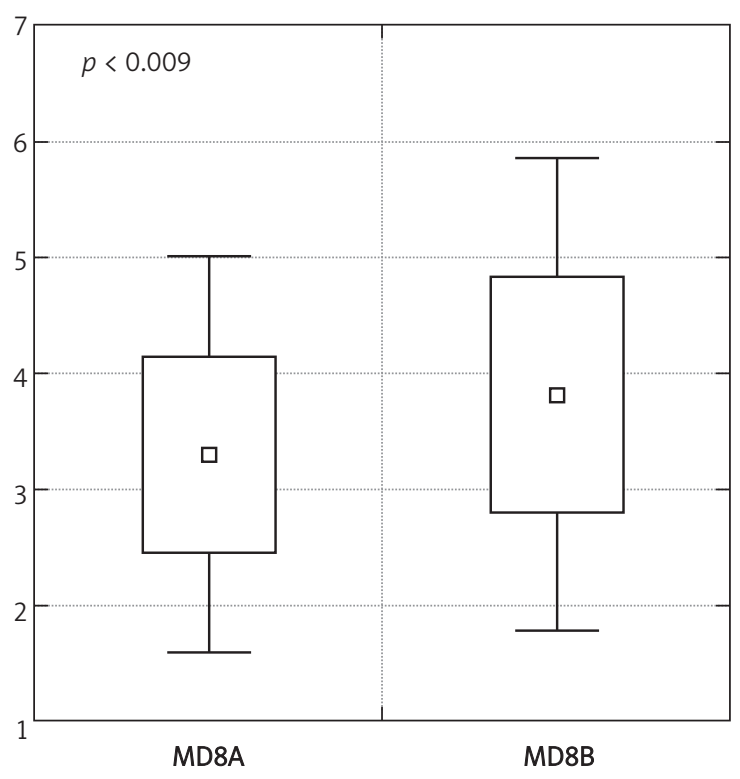

$$
\begin{aligned}
& I \text { Mean }+2^{*} \mathrm{SD}, \text { Mean }-2^{*} \mathrm{SD} \\
& \square \text { Mean }+1^{*} \mathrm{SD}, \text { Mean }-1^{*} \mathrm{SD} \\
& \square \text { Mean }
\end{aligned}
$$

Figure 2. Changes of the mean duration of the peristaltic contraction at the level of 3 and $8 \mathrm{~cm}$ above the LES in the whole study group 
A

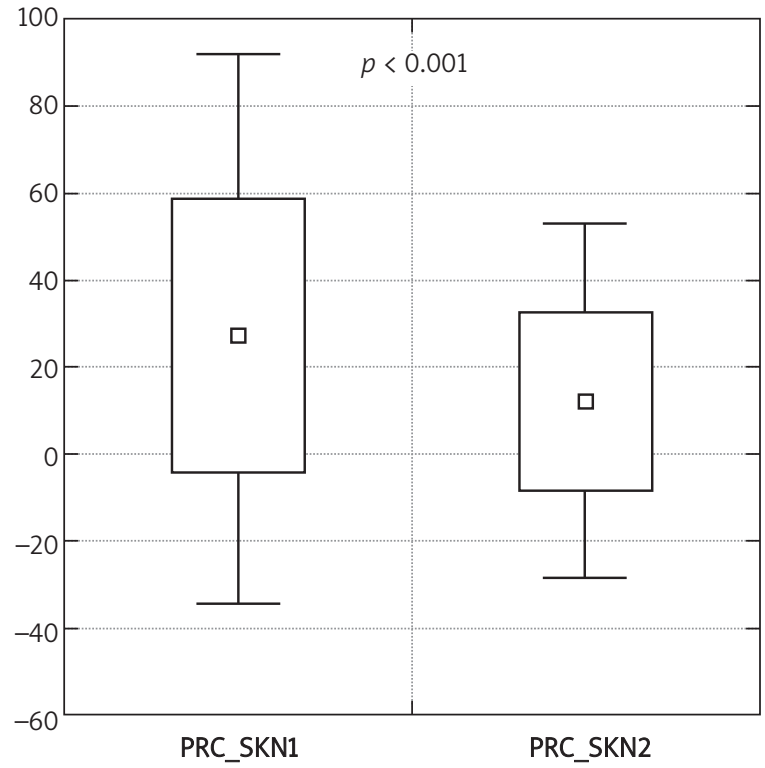

$I$ Mean $+2^{*} \mathrm{SD}$, Mean $-2^{*} \mathrm{SD}$
$\square$ Mean $+1^{*} \mathrm{SD}$, Mean $-1^{*} \mathrm{SD}$
$\square$ Mean
B

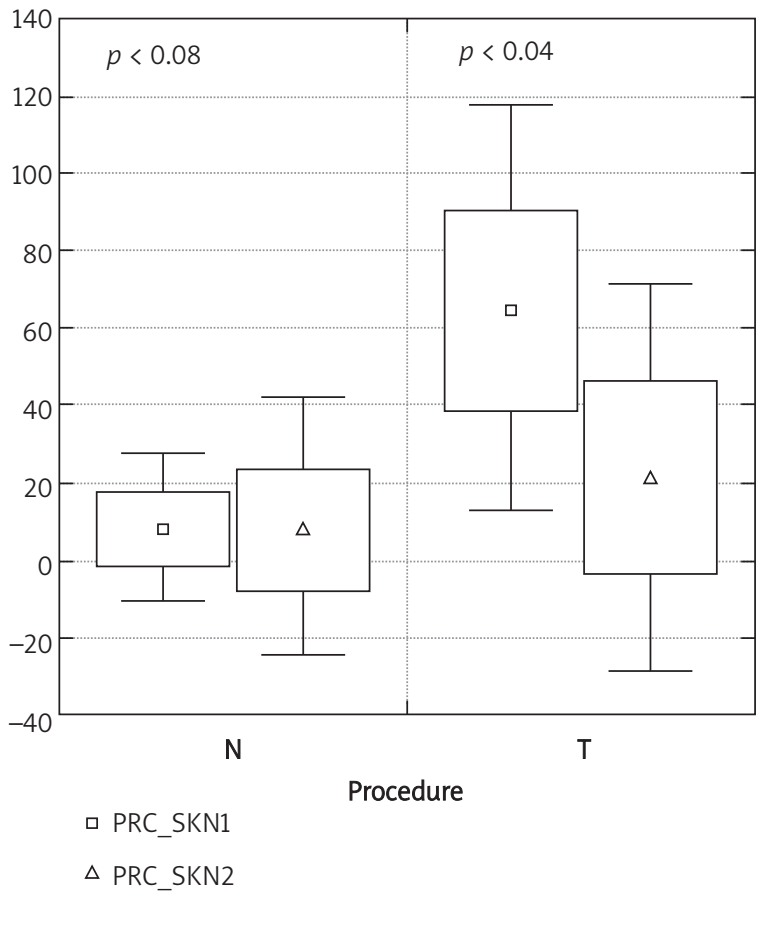

Figure 3. Comparison of non-peristaltic contractions before and after the procedure in the whole study group depending on the procedure type ( $\mathrm{N}$ - Nissen; $\mathrm{T}$ - Toupet)

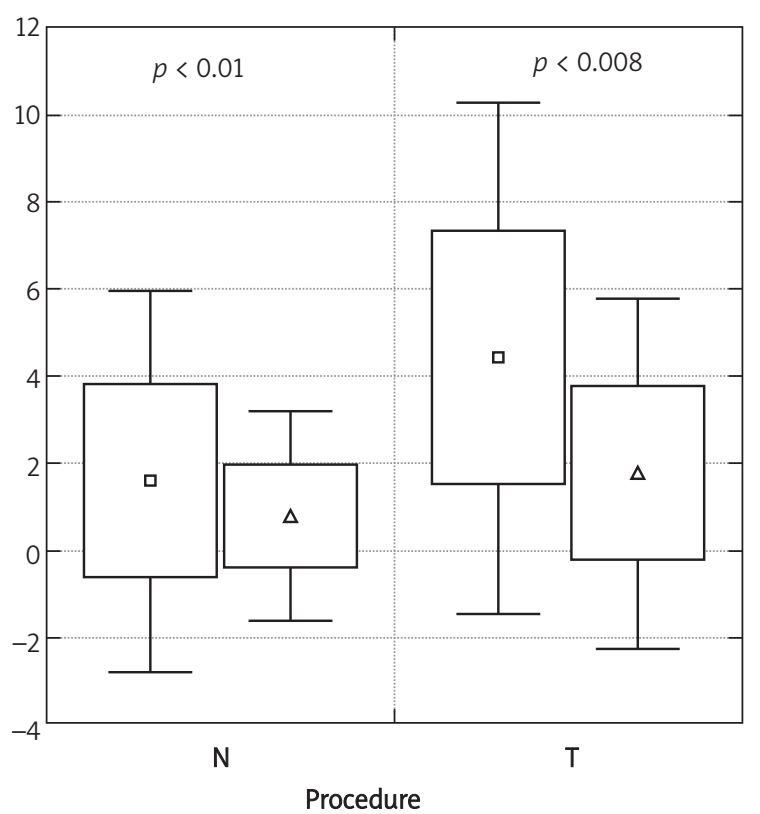

$\begin{array}{ll}\square \text { Mean }+2^{*} \mathrm{SD}, \text { Mean }-2^{*} \mathrm{SD} & \square \mathrm{IL} \text { SKA1 } \\ \square \text { Mean }+1^{*} \mathrm{SD}, \text { Mean }-1^{*} \mathrm{SD} & \Delta \mathrm{IL} \text { SKA2 } \\ \square \text { Mean } & \end{array}$

Figure 4. Comparison of low-amplitude contractions before and after the procedure depending on the procedure type ( $\mathrm{N}$ - Nissen; T - Toupet) peristaltic wave efficacy these changes are not as significant as in the group of patients after Toupet fundoplication.

The number of peristaltic contractions also changed (IL_SKP). The greatest changes of this parameter were observed similarly as in previous cases in patients with primarily impaired oesophageal motility. Following the Toupet procedure an improvement was achieved, that is an increase in the number of peristaltic contractions (IL_SKP1) from 3.8 before to (IL_SKP2) 5.9 after the procedure $(p<0.005)$ (Figure 5).

After the Nissen procedure the absolute number of peristaltic contractions did not change significantly. However, in the whole study population a slight increase from 6.08 to 7.14 ( $p<0.006)$ was observed, though it seems that first of all the changes in the group following the Toupet procedure are responsible for it.

In none of the groups were significant changes regarding the numbers of simultaneous contractions observed. In the whole examined population the number of simultaneous contractions before the procedure was 1.42 and after the procedure 1.75 $(p<0.16)$; in the Nissen fundoplication group it was 
1.28 vs. $1.49(p<0.34)$ respectively; and in the Toupet fundoplication group 1.69 vs. $2.27(p<0.26)$.

\section{Lower oesophageal sphincter assessment}

Restoration of the normal values of the individual parameters in the lower oesophageal sphincter is one of the goals that we set for the properly performed antireflux procedure. Assessing the lower oesophageal sphincter before and after surgery in all patients without the subdivision based on the procedure type, an improvement was achieved in all scrutinized parameters. Total LES length extended from (DLG_LES1) $3.67 \mathrm{~cm}$ to (DLG_LES2) $4.78 \mathrm{~cm}$ $(p<0.001)$; length of the abdominal portion from $1.63 \mathrm{~cm}$ to $4.2 \mathrm{~cm}(p<0.001)$ (Figure 6) and the mean resting pressure in the LES increased from $9.01 \mathrm{mmHg}$ to $16.95 \mathrm{mmHg}$ ( $p<0.001$ ). Equally significant changes of the assessed parameters were achieved in the group of patients after Nissen and Toupet procedure. Following Nissen intervention, the total length of the LES extended from $3.8 \mathrm{~cm}$ (DLG_LES1) to $4.83 \mathrm{~cm}$ (DLG_LES2) $(p<0.001)$; the length of the abdominal portion from $1.69 \mathrm{~cm}$ (DLG_ODB1) to $4.3 \mathrm{~cm}$ (DLG_ODB2) $(p<0.001)$; and the mean resting pressure in the LES increased from $9.61 \mathrm{mmHg}$ (MPV1) before the procedure to $18.12 \mathrm{mmHg}$ (MPV2) after the procedure $(p<0.001)$. In the group of patients following the Toupet procedure the total length of the LES extended from $3.42 \mathrm{~cm}$ (DLG_LES1) to $4.68 \mathrm{~cm}$ (DLG_LES2) $(p<0.001)$; the length of the abdominal portion from $1.51 \mathrm{~cm}$ (DLG_ODB1) to $4.0 \mathrm{~cm}$ (DLG ODB2) $(p<0.001)$; and the mean resting pressure in the LES increased from $7.8 \mathrm{mmHg}$ (MPV1) before to $14.56 \mathrm{mmHg}$ (MPV2) after the procedure $(p<0.002)$ (Figure 7)

In all assessed parameters the maintenance of normal values was observed. Therefore, one can acknowledge that one of the aims of the surgical treatment was achieved. The anatomical antireflux barrier in the gastroesophageal junction was reconstructed and the oesophageal motility improved in the majority of evaluated parameters. The fact that the greatest oesophageal motility improvement appeared in patients with primarily impaired oesophageal motility, especially in the lower, epicardial part of the oesophagus, draws the attention.

\section{Discussion}

Under normal conditions, function of the lower oesophageal sphincter depends on the following parameters:
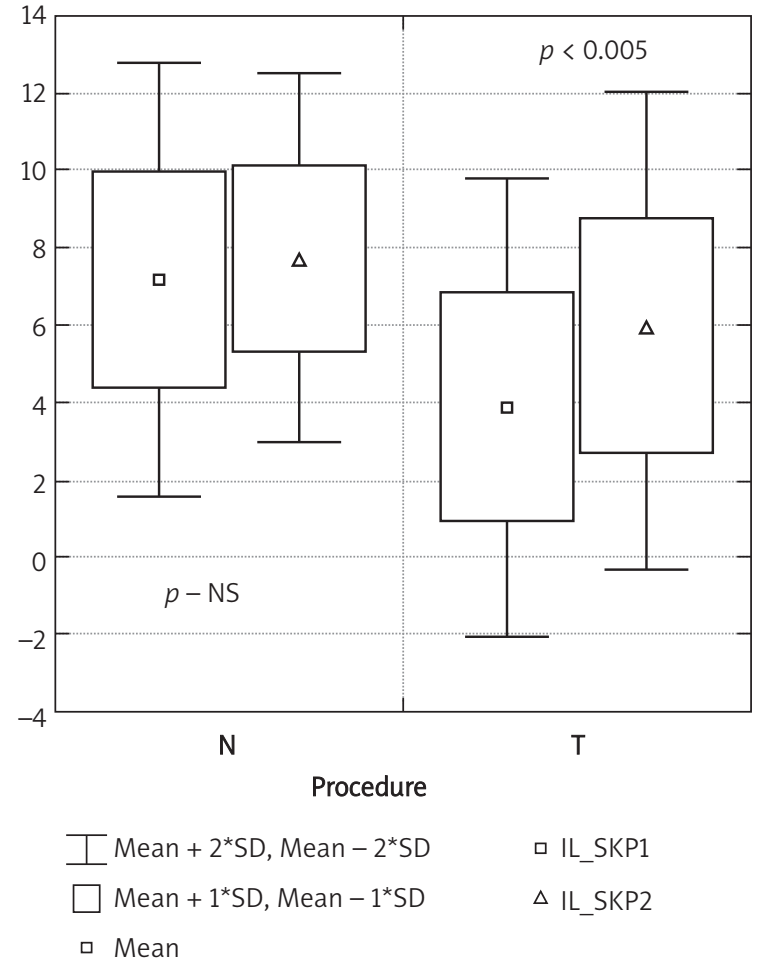

Figure 5. Comparison of numbers of peristaltic contractions before and after the procedure depending on the procedure type ( $\mathrm{N}$ - Nissen; T - Toupet)

- total length,

- length of abdominal portion of LES,

- mean resting pressure.

Change of any of the parameters increases the probability of occurrence of pathological regurgitation from $70 \%$ to $90 \%$. The more factors affected, the greater the insufficiency. With total lack of sphincter function there would be an uninhibited flow of the acidic gastric contents via the gastroesophageal junction and the most severe forms of reflux disease. The most severe damage of the LES occurs in patients with Barrett's oesophagus [20]. Lower oesophageal sphincter insufficiency occurs in $50-60 \%$ of patients with GERD $[2,21]$. In the case of LES function impairment it can be compensated by the correct oesophageal motility function. Identification of LES impairment has a fundamental influence on patients' qualification for surgical treatment. A properly performed procedure is the only prospect for restoration of the correct LES parameters and its physiological function. Considering the results obtained during the study it was noted that the LES damage in the preop- 
A

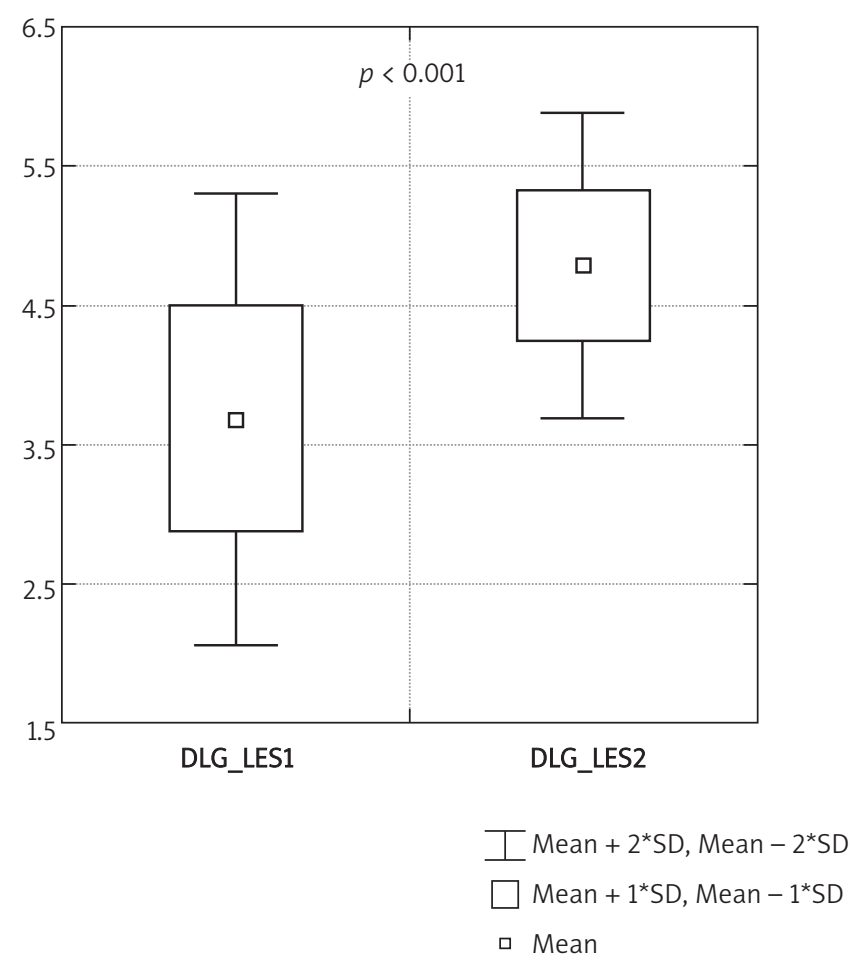

B

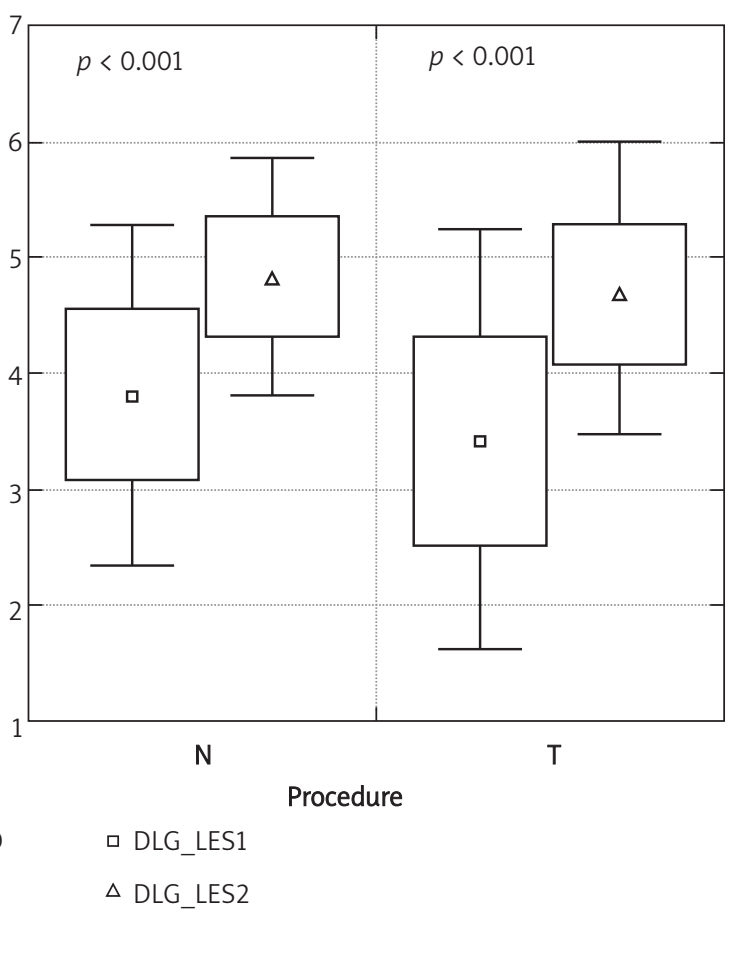

Figure 6. Comparison of the total length of the LES before and after the procedure in the whole study group depending on the procedure type ( $\mathrm{N}$ - Nissen; $\mathrm{T}$ - Toupet)

erative period was one of the essential pathophysiological factors of reflux disease. The mean length of the LES in the evaluation of all patients without the subdivision into groups was $3.67 \mathrm{~cm}$, the length of the abdominal portion of LES was $1.63 \mathrm{~cm}$, and the mean resting pressure was $9.01 \mathrm{mmHg}$. After the procedure these values changed significantly: the mean length of the LES increased to $4.78 \mathrm{~cm}$ $(p<0.001)$, the length of the abdominal portion of LES increased to $4.2 \mathrm{~cm}(p<0.001)$, and the mean resting pressure rose to $16.95 \mathrm{mmHg}(p<0.001)$. The increase was statistically significant in all three parameters. Similar results were obtained after division into groups. However, following the Nissen procedure the LES elongation was greatest $(4.83 \mathrm{~cm})$, the length of the abdominal portion of LES was $4.3 \mathrm{~cm}$, and the mean resting pressure increased most (18.12 $\mathrm{mmHg}$ ). Following the Toupet procedure the total length of the LES was $4.68 \mathrm{~cm}$, the length of the abdominal portion of the LES was $4.0 \mathrm{~cm}$, and the mean resting pressure was $14.56 \mathrm{mmHg}$. Statistical significance was achieved in all parameters irrespective of the fundoplication type. Assessing the efficacy of the procedure in terms of the given parameters it can be said that the procedure restored the normal values; moreover, the elongation of the abdominal portion of the LES exceeded the standard values. The mean length for individual groups is above the 95th percentile. Due to surgery, irrespective of performance of Nissen or Toupet fundoplication, the main component of the anatomical antireflux barrier was restored.

The oesophageal ability of self-purification, that is the oesophageal clearance, depends on:

- gravitational force,

- oesophageal motility,

- properties of and secretion of saliva,

- anchorage of the lower part of the oesophagus below the diaphragm.

The gravitational force and properties of the secreted saliva in the presented material were not assessed, although the buffer capacity of the saliva has an important part in the neutralization of the gastric secretions regurgitated to the oesophagus. The above presented analysis of the LES parameters, in particular the length of the abdominal portion of 
the oesophagus, gives evidence of correct anchorage of the lower part of the oesophagus below the diaphragm. In studies on peristaltic wave efficacy it was found that the peristaltic wave is effective, i.e. it pushes the food bolus towards the stomach, if the contraction amplitude in the proximal part is not lower than $16 \mathrm{mmHg}$, and in the distal part $30 \mathrm{mmHg}$ $[22,23]$. In a considerable number of patients with reflux disease the oesophageal motility is impaired $[22,24,25]$. Motility impairment is present in about $25 \%$ of patients with mild GERD and in about $50 \%$ of patients with severe form of the disease $[12,26]$. It is unknown if the oesophageal motility impairment is a consequence of the longstanding inflammatory process or the primarily occurring motility disturbances lead to the reflux disease.

Analysing data regarding oesophageal motility, it is visible that significant changes in oesophageal motility refer to most of the parameters. In the oesophageal motility assessment before and after the procedure for all patients regardless of the procedure type it was concluded that mainly the changes regarding the increase of the number of peristaltic contractions (6.08 vs. 7.14 ; $p<0.006$ ); the decrease of the number of low-amplitude contractions (2.51 vs. 1.12; $p<0.003$ ) and the reduction of the proportion of non-peristaltic contractions (26.86\% vs. $12.2 \% ; p<0.001)$ are significant for motility and oesophageal clearance improvement. Remaining values, such as the mean amplitude of the contraction and the mean time of the peristaltic contraction despite the changes, that in some of the parameters reached statistical significance, do not have a substantial influence on the peristaltic contraction efficacy because they remain within the range of standard values all the time, both before and after the procedure. The oesophageal motility following the Nissen procedure changes in the extent of: the decrease of the number of low-amplitude contractions ( 1.56 vs. $0.8 ; p<0.01$ ); the change of the peristaltic contraction duration that prolongs at each level of the oesophageal corpus and in all cases changes statistically significantly. The meaning of this fact is difficult to interpret because these values before and after the procedure are within the normal range of values. The mean amplitude of the peristaltic contraction changes significantly only at the level of $3 \mathrm{~cm}$ above the LES (1.56 vs. $0.8 ; p<0.01$ ) and can be directly connected with the increase of the resting pressure in the LES. From a purely

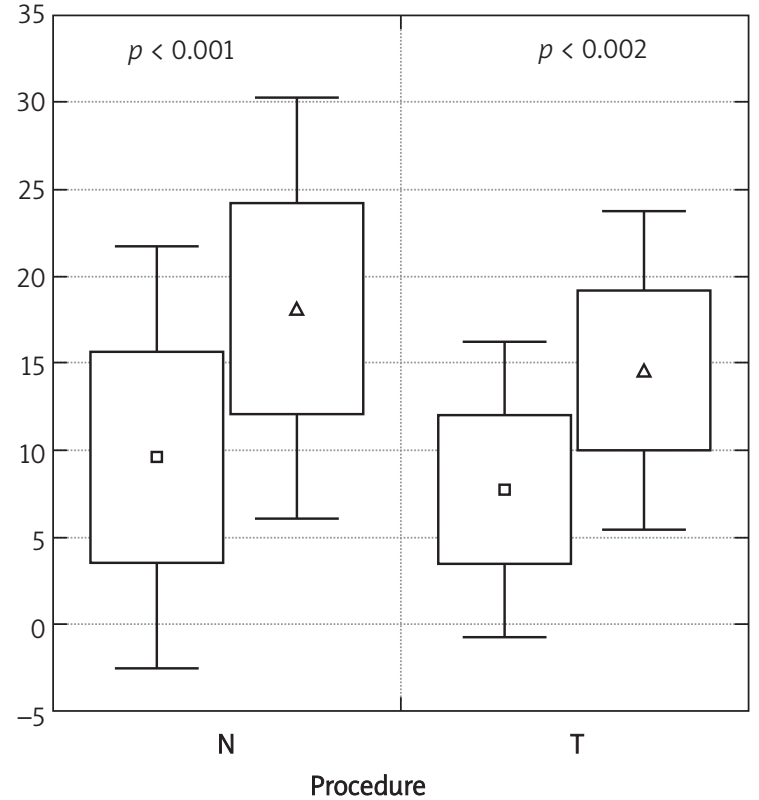

$\begin{array}{ll}I \text { Mean }+2^{*} \mathrm{SD}, \text { Mean }-2^{*} \mathrm{SD} & \square \mathrm{MPV} 1 \\ \square \text { Mean }+1^{*} \mathrm{SD}, \text { Mean }-1^{*} \mathrm{SD} & \triangle \mathrm{MPV} 2 \\ \square \text { Mean } & \end{array}$

Figure 7. Comparison of the mean resting pressure in the LES before and after the procedure in the whole study group depending on the procedure type ( $\mathrm{N}$ - Nissen; $\mathrm{T}$ - Toupet)

mechanical point of view higher amplitude of the oesophageal peristaltic contraction might be required to overcome higher resistance in the lower oesophageal sphincter. Changes of the contraction amplitude are more pronounced after the Toupet intervention. Analysing the whole group, the mean amplitude of peristaltic contraction improves at all levels of the oesophagus, while the mean duration of the peristaltic contraction changes significantly only in the lower part of the oesophagus. In the detailed analysis one can see that the improvement does not apply to all patients. In this group 54\% of patients had profound impairment of the contraction amplitude. The mean contraction amplitude at 10 moist swallows $3 \mathrm{~cm}$ above the LES was below $30 \mathrm{mmHg}$. An improvement of the amplitude was observed in $73 \%$ of patients and in particular in the epicardial part of the oesophagus following the procedure. On the other hand, very significant improvement is seen in the decrease of the proportion of non-peristaltic contractions, $64.2 \%$ vs. $21.5 \%$ $(p<0.004)$; in the rise of the absolute number of 
peristaltic contractions, 3.8 vs. $5.9(p<0.005)$; and the reduction of the number of low-amplitude contractions 4.42 vs. $1.75(p<0.008)$. Analysing the presented data, the changes having a significant impact on oesophageal motility were observed mainly after the Toupet procedure. The proportion of peristaltic contractions, increase of the number of peristaltic contractions and the decrease of the number of lowamplitude contractions are the objective parameters that returned to the normal range of values following the procedure. It seems that antireflux surgery regardless of the technique used influences the improvement of the lower oesophageal sphincter parameters, thereby restoring the antireflux barrier in the gastroesophageal junction. The oesophageal motility improvement is more pronounced after the Toupet procedure, and therefore in the group of patients with primarily impaired motility. A very important observation is also that there is an association between the presence of severe inflammatory changes in the oesophagus and the oesophageal motility impairment. The more severe the inflammatory changes, the more impaired the motility. Which is the cause and which is the effect remains unsolved. The fact is that following the procedure severe inflammatory changes in the oesophagus heal and the impaired motility in this group radically improves [9, 15, 16, 18, 27-34].

\section{Conclusions}

1. Antireflux procedures regardless of the technique used cause normalization of lower oesophageal sphincter function. All anatomical parameters of the lower oesophageal sphincter return to normal values.

2. Following the antireflux procedures the oesophageal motility significantly improves clinically, especially in the group of patients with impaired oesophageal motility. Improvement of oesophageal motility occurs mainly in the epicardial part.

\section{References}

1. Policy and Position Statement. An American Gastroenterological Association Medical Position Statement on the Clicinal Use of Esophageal Manometry. Gastroenterology 1994; 107: 1865-84.

2. Stein HJ, Korn O. Pathophysiology of esophageal motor disorders and gastroesophageal reflux disease. In: Modern approach to benign esophageal disease. Diagnosis and surgical therapy. Bremner CG, DeMeester TR, Peracchia A (eds.). St. Louis, Missouri 1995; 1-16.
3. Costantini M, DeMeester TR. Preoperative assessment of esophageal function. In: Modern approach to benign esophageal disease. Diagnosis and surgical therapy. Bremner CG, DeMeester TR, Peracchia A (eds.). St. Louis, Missouri 1995; 17-56.

4. Crookes PF, Stein HJ, DeMeester TR. Stationary manometry of the esophageal body and upper esophageal sphincter. Problems in General Surgery. Tests of Foregut.

5. Dent J, Holloway RH. Esophageal motility and reflux testing. Gastroenterol C N Am 1996; 25: 51-71.

6. DiMarino AJ, Allen ML, Lynn RB, Zamani S. Clinical value of esophageal motility testing. Dig Dis 1998; 16: 198-204.

7. Donahue PE. Basic considerations in gastroesophageal reflux disease. Surg CI N Am 1997; 77: 1017-40.

8. Richter JE. Oesophageal motility disorders. Lancet 2001; 358: 823-8.

9. Deprez P, Fiasse R. Healing of severe esophagitis improves esophageal peristaltic dysfunction. Dig Dis Sci 1999; 44: 125-33.

10. Fouad YM, Katz PO, Hatlebakk JG, Castell DO. Ineffective esophageal motility: the most common motility abnormality in patients with GERD - associated respiratory symptoms. Am J Gastroenterol 1999; 94: 1464-7.

11. Howard JM, Reynolds RP, Frei JV, et al. Macroscopic healing of esophagitis does not improve esophageal motility. Dig Dis Sci 1994; 39: 648-54.

12. Kahrilas PJ, Dodds WJ, Hogan WJ, et al. Esophageal peristaltic dysfunction in peptic esophagitis. Gastroenterology 1986; 91 : 897-904.

13. Rydberg L, Ruth M, Abrahamsson H, Lundell L. Tailoring antireflux surgery: a randomized clinical trial. World J Surg 1999; 23 : 612-8.

14. Singh P, Adamopoulos A, Taylor RH, Colin-Jones DG. Oesophageal motor function before and after healing of oesophagitis. Gut 1992; 33: 1590-6.

15. Stein HJ, Bremmer RM, Jamieson J, DeMeester TR. Effect of Nissen fundoplication on esophageal motor function. Arch Surg 1992; 127: 788-91.

16. Swanstrom LL, Jobe BA, Kinzie LR, Horvath KD. Esophageal motility and outcomes following laparoscopic paraesophageal hernia repair and fundoplication. Am J Surg 1999; 177: 359-63.

17. Tarnowski W, Ciesielski A, Pertkiewicz J, et al. Laparoskopowe leczenie refluksu żołądkowo-przełykowego. Videochirurgia 2000; 5: 2-14.

18. Timmer R, Breumelhof R, Nadorp JH, Smout AJ. Oesophageal motility and gastro-oesophageal reflux before and after healing of reflux oesophagitis. A study using 24 hour ambulatory $\mathrm{pH}$ and pressure monitoring. Gut 1994; 35: 1519-22.

19. Castell DO. Esophageal manometry prior to antireflux surgery: required, preferred, even needed? Gastroenterology 2001; 121: 214-20.

20. Clark GWB. Barrett's esophagus: pathophysiology and management. In: Modern approach to benign esophageal disease. Diagnosis and surgical therapy. Bremner CG, DeMeester TR, Peracchia A (eds.). St. Louis, Missouri 1995; 69-82.

21. Wallner G. Fundoplikacja Nissena Rossetti'ego w chirurgicznym leczeniu choroby z zarzucania żołądkowo-przełykowego. Rozprawa habilitacyjna, Lublin 1996. 
22. Anggiansah A, Taylor G, Bright N, et al. Primary peristalsis is the major acid clearance mechanism in reflux patients. Gut 1994; 35: 1536-42.

23. Patti MG, Bresadola V. Gastroesophageal reflux disease: basic consoderations. Problem in General Surgery 1996; 12: 1-8.

24. Bittinger M, Barnert J, Wienbeck M. Pathogenesis of gastroesophageal reflux disease. Buchler MW, Frei E, Klaiberg Ch, Krahenbuhl L (eds). Gastroesophageal reflux disease (GERD): back to surgery? Prog Surg Basel Karger 1997; 23: 1-8.

25. Kahrilas PJ. Esophageal motor activity and acid clearance. Gastroenterol C N Am 1990; 19: 537-50.

26. Bell RCW, Hanna P, Powers B, et al. Clinical and manometric results of laparoscopic partial (Toupet) and complete (RosettiNissen) fundoplication. Surg Endosc 1996; 10: 724-8.

27. Escandell AO, Martinez de Haro LF, Paricio PP, et al. Surgery improves defective oesophageal peristalsis in patients with gastro-oesophageal reflux. Br J Surg 1991; 78: 1095-7.

28. Fibbe Ch, Layer P, Keller J, et al. Esophageal motility in reflux disease before and after fundoplication: a prospective, randomized, clinical, and manometric study. Gastroenterology 2001; 121: 5-14.

29. Mathew G, Watson DI, Myers JC, et al. Oesophageal motility before and after laparoscopic Nissen fundoplication. Br J Surg 1997; 84: 1465-9.

30. Rydberg L, Ruth M, Lundell L. Does oesophageal motor function improve with time after successful antireflux surgery? Results of a prospective, randomised clinical study. Gut 1997; 41: 82-6.

31. Vassilakis JS, Xynos E, Kasapidis P, et al. The effect of floppy Nissen fundopliaction on esophageal and gastric motility in gastroesophageal reflux. Surg Gynecol Obstet 1993; 177: 608-16.

32. Zaninotto G, Constantini M, Anselmino M, et al. Oesophageal and cardia function in patients with paraoesophageal hiatus hernia. Br J Surg 1997; 84: 1163-7.

33. Zornig C, Strate U, Fibbe C, et al. Nissen vs Toupet laparoscopic fundoplication. A prospective randomized study of 200 patients with and without preoperative esophageal motility disorders. Surg Endosc 2002; 16: 758-66.

34. Wallner G, Solecki M, Tarnowski W, et al. Gastroesophageal reflux disease - clinical practice guidelines. Videosurgery and other miniinvasives techniques 2009; 4 Suppl. 1: 16-24.

35. Wróblewski T, Grodzicki M, Ziarkiewicz-Wróblewska B. Aspekty techniczne i wyniki laparoskopowej fundoplikacji sposobem Toupet w leczeniu zaawansowanej postaci refluksu żołądkowoprzetykowego (GERD). Videosurgery and other miniinvasives techniques 2006; 1: 6-9. 